\title{
Prediction of Progressive Failure Behaviour of Composite Skewed Hypar Shells Using Finite Element Method
}

\author{
Arghya Ghosh and Dipankar Chakravorty \\ Civil Engineering Department, Jadavpur University, Kolkata 700032, India \\ Correspondence should be addressed to Arghya Ghosh; arghyaghosh698@gmail.com
}

Received 19 May 2014; Accepted 20 August 2014; Published 16 September 2014

Academic Editor: Hanxing Zhu

Copyright (C) 2014 A. Ghosh and D. Chakravorty. This is an open access article distributed under the Creative Commons Attribution License, which permits unrestricted use, distribution, and reproduction in any medium, provided the original work is properly cited.

\begin{abstract}
Progressive failure behaviour of laminated composite skewed hypar shells is investigated in this paper through finite element approach. For composite materials which are weak in transverse shear, failure may initiate at any inner lamina or interface and may remain undetected and unattended to. Such latent damages may progress gradually and lead to a sudden total ply failure. An iterative method is adopted using the various failure theories to predict the first ply failure load. After the first ply failure, the stiffness of the failed element is totally discarded from the laminate and the remaining laminate is considered for further analysis. The developed finite element code is validated through solution of a benchmark problem. Numerical experiments are carried out to obtain the first ply and progressive failure of simply supported hypar shells under transverse distributed load. While obtaining the failure loads, the shell is considered to be under plane stress condition and in linear elastic range. Results are studied meticulously to extract a set of conclusions of practical significance regarding the failure characteristics of composite hypar shells.
\end{abstract}

\section{Introduction}

In modern engineering and technology, a composite is defined as a material composed of stacked layers with fiber reinforcement held in proper location with the rigid binder. A number of laminae are bonded together to obtain a "laminate" which stands for a structural unit of a beam, plate, or shell. Nowadays researchers are emphasizing more on laminated composite shells realizing the strength and stiffness potentials of this advanced material. Shell structures are preferred in the industry to cover large column free open spaces as are found in airports, shopping malls, auditoriums, and car parking lots. A skewed hypar shell is aesthetically appealing and being doubly ruled is easy to cast. Moreover, this configuration can allow entry of north light and due to this advantage it finds use as roofing units in practical civil engineering applications. Researchers like Sahoo and Chakravorty [1,2] and Nayak and Bandyopadhyay [3] studied bending and vibration characteristics of graphite-epoxy hypar shells.

It is important to note that failure study of the laminated hypar shell is needed for their confident application in the industry. First and ultimate ply failure of composite plates have received attention from researchers like Singh and Kumar [4], Akhras and Li [5], and Ganesan and Liu [6] who reported that failure of the laminated composites is progressive in nature and the load at which failure initiates (first ply failure load) in the laminates is much lower than its ultimate load carrying capacity. First ply failure of laminated plates and shells also reported by Reddy and Pandey [7], Kam and Jan [8], Kam et al. [9] Prusty et al. [10], and Satish Kumar and Srivastava [11]. The progressive failure analysis of laminated composite plates under transverse static loading was carried out in linear and elastic range by Pal and Ray [12]. Philippidis and Antoniou [13] computed a progressive failure analysis model for glass/epoxy composite giving an extensive comparison between numerically calculated stress-strain response up to failure and experimental data. Very recently, Ellul et al. [14] studied progressive failure analysis of fiber reinforced composite plates subjected to out-of-plane bending. Tolson and Zabaras [15] developed two-dimensional finite element analysis for determining progressive failure in composite plates using seven degrees of freedom. A first ply and progressive failure analysis of laminated unstiffened 


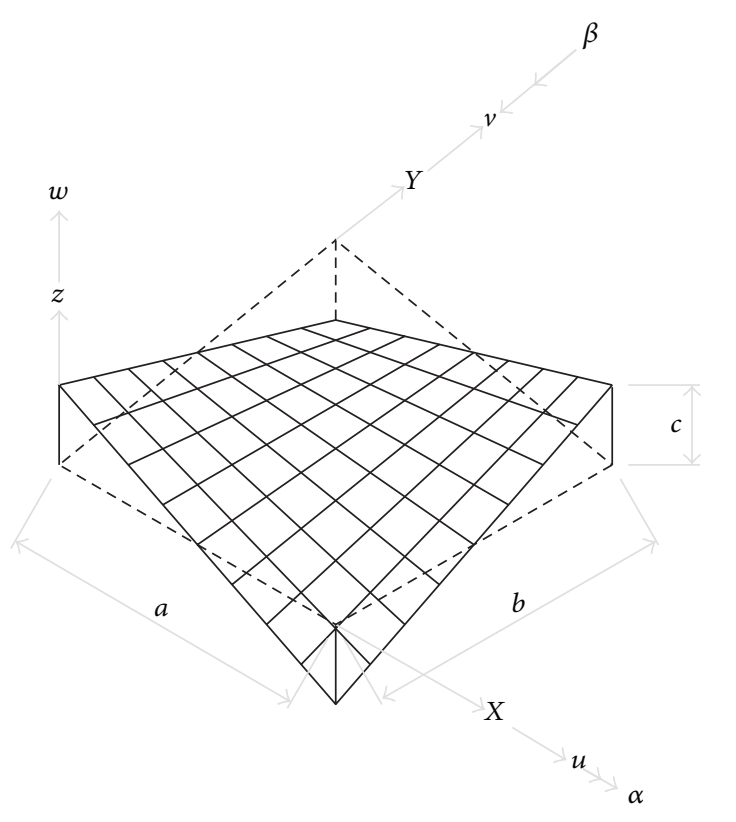

FIGURE 1: A typical hypar shell surface.

and stiffened composite panels under static loadings were investigated by Prusty [16] using the geometric and material linearity.

It is noted from the literature review that the failure aspects of industrially important hypar shell is totally missing. To fulfill this lacuna the present investigation intends to study the failure progress of hypar shell by a linear finite element approach from practical engineering point of view.

\section{Mathematical Formulation}

A laminated composite hypar shell (Figure 1) of uniform thickness $h$ and twist radius of curvature $R_{x y}$ is considered. Keeping the total thickness the same, the thickness may consist of any number of thin laminae each of which may be arbitrarily oriented at an angle $\theta$ with reference to the $X$ axis of the coordinate system. The surface equation of this shell is

$$
z=\frac{4 c}{a b}\left(x-\frac{a}{2}\right)\left(y-\frac{b}{2}\right) .
$$

The radius of cross curvature may be evaluated by differentiating the surface equation of shell and for shallow shells which are taken up for the present study the same may be expressed as $1 / R_{x y}=\delta^{2} z / \delta x \delta y=4 c / a b$.

An eight-noded curved quardratic isoparametric element (Figure 2) having five degrees of freedom at each node which includes the in-plane, transverse displacements, and slopes along the plan directions. The governing equations and the systematic development of the stiffness matrix of the shell have been reported in Sahoo and Chakravorty [2].

The strain-displacement relation is given by

$$
\{\varepsilon\}=[B]\left\{d_{e}\right\},
$$

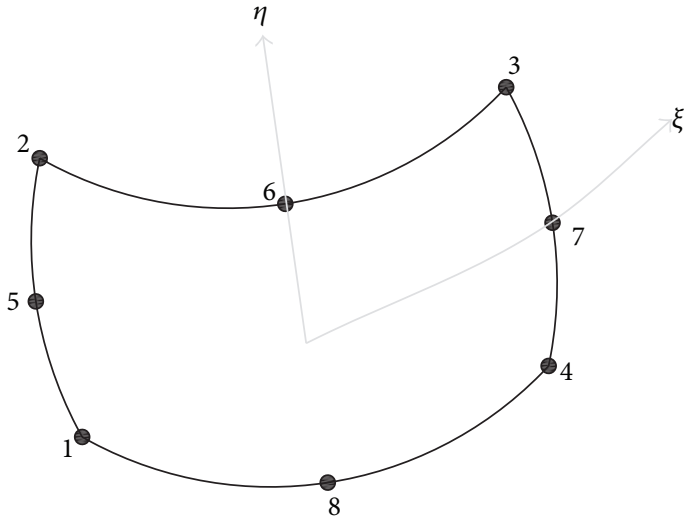

FIGURE 2: An eight-noded finite element.

where $\left\{d_{e}\right\}=\left\{\begin{array}{lllllllllll}u_{1} & v_{1} & w_{1} & \alpha_{1} & \beta_{1} & \cdots & u_{8} & v_{8} & w_{8} & \alpha_{8} & \beta_{8}\end{array}\right\}^{T}$ and

$$
[B]=\sum_{i=1}^{8}\left[\begin{array}{ccccc}
N_{i, x} & 0 & 0 & 0 & 0 \\
0 & N_{i, y} & 0 & 0 & 0 \\
N_{i, y} & N_{i, x} & -\frac{2 N_{i}}{R_{x y}} & 0 & 0 \\
0 & 0 & 0 & N_{i, x} & 0 \\
0 & 0 & 0 & 0 & N_{i, y} \\
0 & 0 & 0 & N_{i, y} & N_{i, x} \\
0 & 0 & N_{i, x} & N_{i} & 0 \\
0 & 0 & N_{i, y} & 0 & N_{i}
\end{array}\right] .
$$

In-plane strain components for a lamina situated at a distance " $z$ " from the lamina mid-plane are evaluated in global axes as

$$
\begin{aligned}
\varepsilon_{x} & =\varepsilon_{x}^{0}+z k_{x}, \\
\varepsilon_{y} & =\varepsilon_{y}^{0}+z k_{y}, \\
\gamma_{x y} & =\gamma_{x y}^{0}+z k_{x y} .
\end{aligned}
$$

Lamina strains are transformed from the global axes of the shell to the local axes of the lamina using the following transformation matrix:

$$
\left\{\begin{array}{l}
\varepsilon_{1} \\
\varepsilon_{2} \\
\frac{\varepsilon_{6}}{2}
\end{array}\right\}=\left[\begin{array}{ccc}
m^{2} & n^{2} & 2 m n \\
n^{2} & m^{2} & -2 m n \\
-m n & m n & m^{2}-n^{2}
\end{array}\right]\left\{\begin{array}{c}
\varepsilon_{x} \\
\varepsilon_{y} \\
\frac{\varepsilon_{x y}}{2}
\end{array}\right\},
$$

where $m=\sin \theta, \quad n=\cos \theta$.

Lamina stresses are obtained using the following constitutive relation of the lamina:

$$
\left\{\begin{array}{l}
\sigma_{1} \\
\sigma_{2} \\
\sigma_{6}
\end{array}\right\}=\left[\begin{array}{ccc}
Q_{11} & Q_{12} & 0 \\
Q_{12} & Q_{22} & 0 \\
0 & 0 & Q_{66}
\end{array}\right]\left\{\begin{array}{l}
\varepsilon_{1} \\
\varepsilon_{2} \\
\varepsilon_{6}
\end{array}\right\},
$$

where $Q_{11}=\left(1-v_{12} v_{21}\right)^{-1} E_{11}, Q_{22}=\left(1-v_{12} v_{21}\right)^{-1} E_{22}, Q_{12}=$ $\left(1-v_{12} \nu_{21}\right)^{-1} E_{11} \nu_{21}$, and $Q_{66}=G_{12}$. 
The basic problem of static takes the following form:

$$
[K]\{d\}=\{P\},
$$

where $[K]$ is the overall stiffness matrix and $\{d\}$ and $\{P\}$ are generalized displacement and load vectors, respectively. The above equation is solved by Gauss elimination technique and from the global nodal displacement vector $\{d\}$ thus obtained, the element displacement vectors $\left\{d_{e}\right\}$ are known. Using $\left\{d_{e}\right\}$ in ((2)) the strains can be evaluated at the Gauss points, which give the generalized force and moment resultants at the Gauss points. The stresses are obtained using the stressstrain constitutive relationship. Lamina stresses are used in well-accepted failure theories like maximum stress, Tsai-Hill, Tsai-Wu, and Hoffman failure criteria, shown in ((8)) to ((11)), to evaluate the first ply and ultimate ply failure loads of the composite hypar shells under present study.

Maximum Stress Failure Criteria. According to maximum stress theory, the failure initiates if at least one of the following criteria is satisfied:

$$
\begin{aligned}
& \frac{\sigma_{1}}{X} \geq 1, \\
& \frac{\sigma_{2}}{Y} \geq 1, \\
& \frac{\tau_{12}}{S} \geq 1,
\end{aligned}
$$

where

$\sigma_{1}=$ Normal stress along 1st direction, that is, along the direction of lamina.

$\sigma_{2}=$ Normal stress along 2nd direction, that is, along the perpendicular direction of lamina.

$X$ and $Y=$ Strength of the material in failure along 1st and 2 nd direction, respectively.

$\tau_{12}=$ Shear stress in the 1-2 plane.

$S=$ Shear strength of the material.

Tsai-Hill Criteria. According to this theory, the first ply failure occurs when the following criteria are satisfied in any one of the laminae:

$$
\left(\frac{\sigma_{1}}{X}\right)^{2}+\left(\frac{\sigma_{2}}{Y}\right)^{2}-\left(\frac{1}{X^{2}}+\frac{1}{Y^{2}}\right) \sigma_{1} \sigma_{2}+\left(\frac{\tau_{12}}{S}\right)^{2} \geq 1,
$$

where

$\sigma_{1}$ and $\sigma_{2}=$ Normal stress along 1 st and 2nd direction, respectively.

$X$ and $Y=$ Strength of the material in failure along 1st and 2 nd direction, respectively.

$\tau_{12}=$ Shear stress in the 1-2 plane.

$S=$ Shear strength of the material.
Tsai-Wu Criteria. According to this theory the first ply failure occurs when the following criteria are satisfied in any one of the laminae:

$$
\begin{aligned}
& \left(\frac{1}{X_{T}}-\frac{1}{X_{C}}\right) \sigma_{1}+\left(\frac{1}{Y_{T}}-\frac{1}{Y_{C}}\right) \sigma_{2}+\left(\frac{1}{X_{T} X_{C}}\right) \sigma_{1}^{2} \\
& +\left(\frac{1}{Y_{T} Y_{C}}\right) \sigma_{2}^{2}-\frac{1}{2}\left(\sqrt{X_{T} X_{C} Y_{T} Y_{C}}\right) \sigma_{1} \sigma_{2} \\
& +\left(\frac{\tau_{12}}{S}\right)^{2} \geq 1,
\end{aligned}
$$

where

$X_{T}$ and $Y_{T}=$ Tensile strength along 1st and 2nd direction, respectively.

$X_{C}$ and $Y_{C}=$ Compressive strength along 1st and 2nd direction, respectively.

$\sigma_{1}$ and $\sigma_{2}=$ Normal stress along 1st and 2nd direction, respectively.

$\tau_{12}=$ Shear stress in the 1-2 plane.

$S=$ Shear strength of the material.

Hoffman's Criteria. According to this theory, the lamina failure is assumed to occur when the following criteria are satisfied:

$$
\begin{aligned}
& \frac{1}{2}\left(\frac{1}{X_{T} X_{C}}-\frac{1}{Y_{T} Y_{C}}\right) \sigma_{1}^{2}+\frac{1}{2}\left(\frac{1}{Y_{T} Y_{C}}-\frac{1}{X_{T} X_{C}}\right) \sigma_{2}^{2} \\
& \quad+\frac{1}{2}\left(\frac{1}{X_{T} X_{C}}+\frac{1}{Y_{T} Y_{C}}\right)\left(\sigma_{1}-\sigma_{2}\right)^{2}+\left(\frac{1}{X_{T} X_{C}}\right) \sigma_{1} \\
& \quad+\left(\frac{\tau_{12}}{S}\right)^{2} \geq 1,
\end{aligned}
$$

where

$X_{T}$ and $Y_{T}=$ Tensile strength along 1st and 2nd direction, respectively.

$X_{C}$ and $Y_{C}=$ Compressive strength along 1st and 2nd direction, respectively.

$\sigma_{1}$ and $\sigma_{2}=$ Normal stress along 1st and 2nd direction, respectively.

$\tau_{12}=$ Shear stress in the 1-2 plane.

$S=$ Shear strength of the material.

After the first ply failure (FPF), the stiffness of the failed element is totally discarded from the laminate and the remaining shell is considered for further analysis. The failed element is replaced with an equivalent element of the degraded material properties. Displacements and stresses are recalculated and the stresses for the remaining shell portions are verified against the selected failure criteria to compute the next failure load and failure point that would fail immediately under the increased share of stresses. The progressive failure 
TABLE 1: Comparison of first ply failure loads for a $\left(0_{2}^{0} / 90^{0}\right)_{s}$ plate.

\begin{tabular}{|c|c|c|c|}
\hline Failure criteria & Side/thickness & $\begin{array}{l}\text { First ply failure loads (Kam et al. [9]) } \\
\text { [Newton] }\end{array}$ & $\begin{array}{l}\text { First ply failure loads (present formulation) } \\
\text { [Newton] }\end{array}$ \\
\hline Maximum stress & \multirow{4}{*}{105.26} & 108.26 & 112.14 \\
\hline Hoffman & & 106.45 & 104.40 \\
\hline Tsai-Wu & & 112.77 & 110.50 \\
\hline Tsai-Hill & & 107.06 & 104.40 \\
\hline
\end{tabular}

TABLE 2: Nondimensional central deflections $\left(\bar{w} \times 10^{3}\right)$ of simply supported composite spherical shell under uniformly distributed load.

\begin{tabular}{lcc}
\hline Lamination & Reddy [17] & Present approach \\
\hline $0^{0} / 90^{0}$ & 16.980 & 17.010 \\
$0^{0} / 90^{0} / 0^{0}$ & 6.697 & 6.701 \\
$0^{0} / 90^{\circ} / 90^{0} / 0^{0}$ & 6.833 & 6.836 \\
\hline$E_{11} / E_{22}=25, G_{12}=G_{13}=0.5 E_{22}, G_{23}=0.2 E_{22}, v_{12}=0.25, a / b=1$, \\
$a / h=100, E_{22}=10^{6} \mathrm{~N} / \mathrm{cm}^{2}$, and $R / a=10^{30}$.
\end{tabular}

study for the shell is carried out using this iterative process, which ultimately achieves the ultimate ply failure (UPF) load. This iterative process is repeated at each load step to investigate the failure of the elements one by one. The ultimate ply failure occurs when it is found that such iterations do not converge. The schematic algorithm of progressive failure is shown Figure 3.

\section{Numerical Problems}

First, ply failure loads obtained from the present formulation are compared with the linear failure loads reported by Kam et al. [9] in Table 1. The results match closely. Also, the results displayed in Table 2 show a good match with the results obtained by Reddy [17] using exact method. This confirms the correct incorporation of hypar shell curvature in the present formulation. For the authors' own problems geometric properties of the skewed hypar shells under simply supported condition and different stacking sequences are presented in Tables 3 and 4, respectively. The Gauss point locations for an element are clearly shown in Figure 4. The Q1115 graphite-epoxy is considered as fabrication material for the shells under present study and the corresponding material properties are reported in Table 5. The shells are subjected to uniformly distributed transverse static loading. The failure loads, failure locations on the shell surface, and the failed lamina, counted from the top of the laminate downwards, correspond to the first ply failure and the ultimate ply failure loads of the laminated composite skewed hypar shells are reported in Table 6.

\section{Results and Discussion}

4.1. First Ply and Ultimate Ply Failure Load. The first ply failure load and ultimate ply failure load for composite skewed hypar shells are mentioned in Table 6. Both the FPF and UPF loads are evaluated using four different well-established
TABLE 3: Geometric dimensions of the hypar shell.

\begin{tabular}{lc}
\hline Hypar shell dimensions & Values $[\mathrm{mm}]$ \\
\hline Length $(a)$ & 1000 \\
Width $(b)$ & 1000 \\
Thickness $(h)$ & 10 \\
Rise of hypar shell $(c)$ & 200 \\
\hline
\end{tabular}

TABLE 4: Different types of lamina.

\begin{tabular}{lc}
\hline Lamina name & Stacking orders \\
\hline Antisymmetric Cross Ply (ASCP) & $0^{0} / 90^{0}$ \\
Symmetric Cross Ply (SYCP) & $0^{0} / 90^{\circ} / 0^{0}$ \\
Antisymmetric Angle Ply (ASAP) & $45^{0} /-45^{0}$ \\
Symmetric Angle Ply (SYAP) & $45^{0} /-45^{0} / 45^{0}$ \\
\hline
\end{tabular}

TABLE 5: Material properties of graphite-epoxy (Q-1115).

\begin{tabular}{lcllrl}
\hline \multicolumn{3}{c}{ Material constants } & \multicolumn{3}{c}{ Strengths } \\
\hline$E_{11}$ & 142.5 & $\mathrm{GPa}$ & $X_{T}$ & 2193.5 & $\mathrm{MPa}$ \\
$E_{22}=E_{33}$ & 9.79 & $\mathrm{GPa}$ & $X_{C}$ & 2457.0 & $\mathrm{MPa}$ \\
$G_{12}=G_{13}$ & 4.72 & $\mathrm{GPa}$ & $Y_{T}=Z_{T}$ & 41.3 & $\mathrm{MPa}$ \\
$G_{23}$ & 1.192 & $\mathrm{GPa}$ & $Y_{C}=Z_{C}$ & 206.8 & $\mathrm{MPa}$ \\
$v_{12}=v_{13}$ & 0.27 & & $R$ & 61.28 & $\mathrm{MPa}$ \\
$v_{23}$ & 0.25 & & $S=T$ & 78.78 & $\mathrm{MPa}$ \\
\hline
\end{tabular}

failure criteria and the minimum value among those is picked up as the failure load. Symmetric angle ply laminate gives the maximum FPF load value while antisymmetric angle ply shows the highest UPF load value. In general the performances of the angle ply shells are better. It may be inferred from the results that among two laminates the one stiffer in terms of FPF may not be the stiffer one in terms of the UPF load. It is also interesting to note that the UPF load is by far higher than the FPF load. In practical civil engineering apart from strength, serviceability is also considered as an important parameter in design. In the present study the permissible deflection is assumed as span/250 (according to Indian Standard IS: 456-2000) which is $4 \mathrm{~mm}$ for the shell geometry considered here. It is very interesting to note that for the cross ply shells, the FPF load corresponds to deflection greater than $4 \mathrm{~mm}$ and for the angle ply shells the deflection corresponding to FPF load is less than $4 \mathrm{~mm}$. In case of angle ply shells when the failure progress is deeply examined it is found that over a wide range of load values one of the plies remains almost undamaged and this accounts for the fact that 


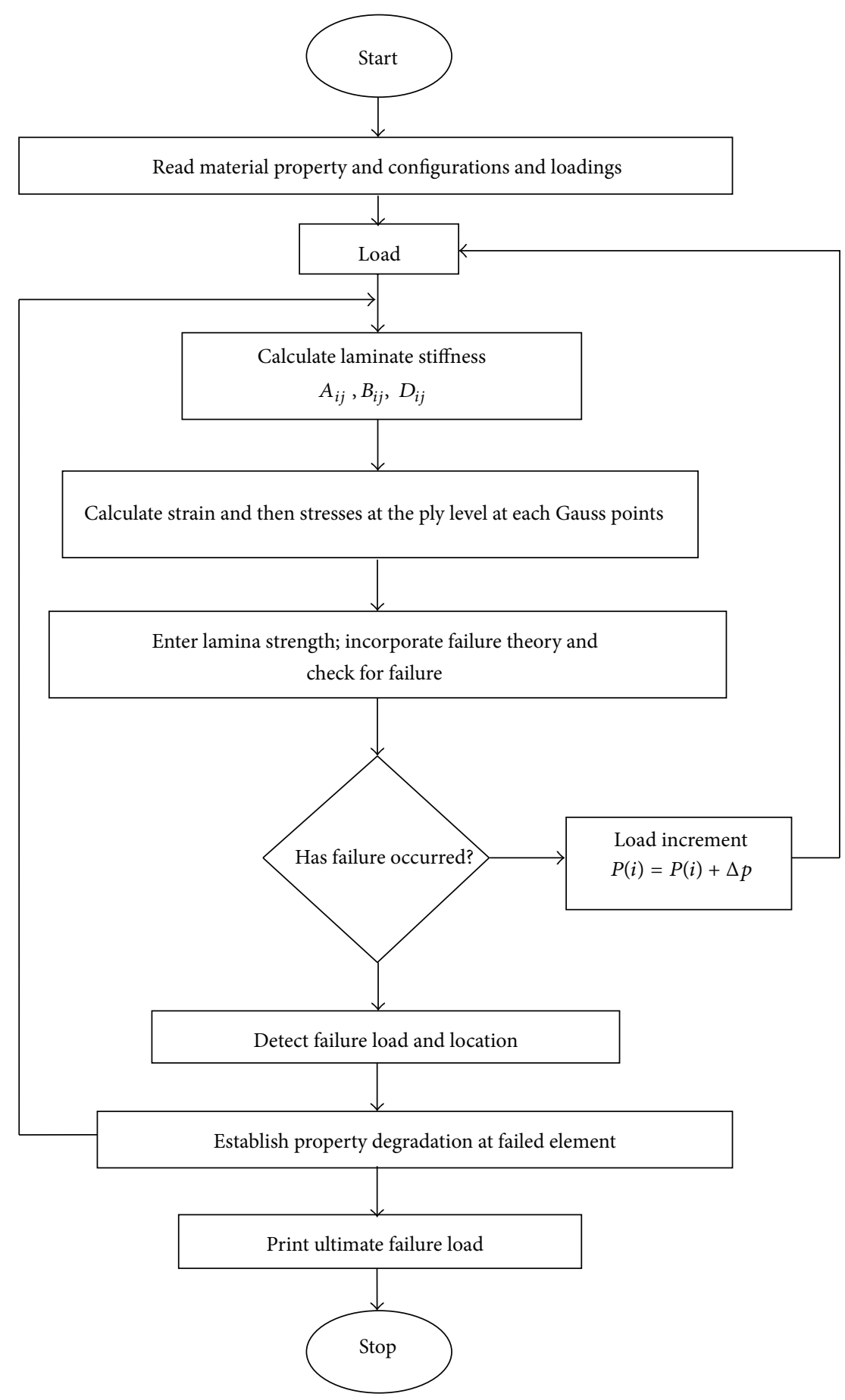

FIGURE 3: Schematic algorithm of progressive failure analysis.

the deflections remain arrested below $4 \mathrm{~mm}$ even when the FPF load is exceeded. The geometry of a skewed hypar shell is such that the shell tends to transfer the loads in the diagonal directions. In the angle ply laminates that are selected here, the fiber directions are aligned along the diagonal directions too. This is why the angle ply shells are in general stiffer than the cross ply ones and deflect less even after getting partly damaged.
4.2. Failure Progress. The failure criterion from which the FPF load is obtained is more important than that of UPF load. This is why the failure progress according to this criterion is studied pictorially in discrete steps and lamina wise. Typical antisymmetric and symmetric angle ply shells are taken up for such study where the failed elements are made dark corresponding to first to fifth ply failure loads and corresponding to 0.25 UPF load, 0.5 UPF load, 0.75 UPF load, 
TABLE 6: First ply failure load and ultimate ply failure load.

\begin{tabular}{|c|c|c|c|c|c|c|c|}
\hline \multirow[b]{2}{*}{$\begin{array}{l}\text { Type of } \\
\text { lamina }\end{array}$} & \multirow[b]{2}{*}{ Failure criteria } & \multicolumn{4}{|c|}{ First ply failure } & \multirow{2}{*}{$\begin{array}{l}\text { Ultimate Ply } \\
\text { Failure Load } \\
(\mathrm{UPFL})[\mathrm{MPa}]\end{array}$} & \multirow{2}{*}{$\begin{array}{c}\text { Load for } 4 \text { mm deflection } \\
\text { where such load is less than } \\
\text { FPFL }[\mathrm{MPa}]\end{array}$} \\
\hline & & $\begin{array}{c}\text { Failure load (FPFL) } \\
{[\mathrm{MPa}]}\end{array}$ & $\begin{array}{c}\text { Failed } \\
\text { ply }\end{array}$ & $\begin{array}{c}\text { Failed } \\
\text { Gauss point }\end{array}$ & $\begin{array}{c}\text { Failed } \\
\text { element }\end{array}$ & & \\
\hline \multirow{4}{*}{ ASCP } & Maximum stress & 0.8238 & 1 & 1 & 8 & 180.0550 & \multirow{4}{*}{0.1993} \\
\hline & Hoffman & $0.7714^{\mathrm{L}}$ & 1 & 1 & 8 & 190.4308 & \\
\hline & Tsai-Hill & 0.8177 & 1 & 1 & 8 & $179.0895^{\mathrm{L}}$ & \\
\hline & Tsai-Wu & 0.7722 & 2 & 1 & 8 & 191.8979 & \\
\hline \multirow{4}{*}{ SYCP } & Maximum stress & 0.7980 & 1 & 1 & 8 & 265.7825 & \multirow{4}{*}{0.1870} \\
\hline & Hoffman & $0.7244^{\mathrm{L}}$ & 2 & 1 & 8 & 296.7450 & \\
\hline & Tsai-Hill & 0.7922 & 1 & 1 & 8 & $265.3874^{\mathrm{L}}$ & \\
\hline & Tsai-Wu & 0.7249 & 2 & 1 & 8 & 300.7547 & \\
\hline \multirow{4}{*}{ ASAP } & Maximum stress & 17.7968 & 2 & 1 & 59 & 499.8536 & \\
\hline & Hoffman & 0.8798 & 1 & 1 & 1 & 495.2707 & \\
\hline & Tsai-Hill & 0.9987 & 1 & 3 & 49 & 509.8078 & \\
\hline & Tsai-Wu & $0.8122^{\mathrm{L}}$ & 1 & 1 & 1 & $493.5450^{\mathrm{L}}$ & \\
\hline \multirow{4}{*}{ SYAP } & Maximum stress & 25.6408 & 1 & 1 & 57 & 504.5590 & \\
\hline & Hoffman & 1.3737 & 1 & 4 & 8 & 356.7432 & \\
\hline & Tsai-Hill & 1.5189 & 1 & 1 & 57 & 418.6368 & \\
\hline & Tsai-Wu & $1.2917^{\mathrm{L}}$ & 1 & 4 & 8 & $328.4164^{\mathrm{L}}$ & \\
\hline
\end{tabular}

Note: "L" represents the least failure load obtained from the four failure criteria.

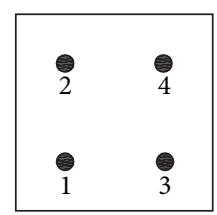

Figure 4: Arrangement of Gauss points $(2 \times 2)$ in an element.

and UPF load. The typical failure pattern of ASCP lamina is shown in Figures 5(a), 5(b), and 5(c).

The lamina-wise failure progress mechanism with gradually increasing failure load and knowledge of failure propagation may be utilised for getting a warning in advance about the gross failure of the shell by appropriate instrumentation related to different nondestructive tests (NDT). If an engineer has a prior knowledge regarding the flow of damage then appropriate points on the shell surfaces may be tested only to detect the hidden flaws without going into an elaborate testing program. The maximum area of damage can be allowed under a practical situation may be correlated with the NDT results at predetermined points.

For example, in case of a $0^{\circ} / 90^{\circ}$ shell, if one has an ultrasonic flaw detection point set up at $x=12.5 \mathrm{~cm}$ and $y=87.5 \mathrm{~cm}$, then once he/she detects a flaw at that point he/she can be sure that area of damage is about $0.8 \%$. In other words if he/she wants to restrict the shell within a maximum limit of $0.8 \%$ damage he/she should be vigilant about the ultrasonic flaw detection results only at the point as mentioned above without going into elaborate instrumentation.

\section{Conclusion}

The present finite element code is capable of successfully assessing the first ply and progressive failure behaviour of laminated composite skewed hypar shells with simply supported boundary condition. The present study indicates that angle ply shells should be preferred compared to cross ply ones from engineering point of view. The location of the first ply failure point is extremely important to be known to a practising engineer because any instrumentation needed for hidden flaw detection should start from that point. In other words, if it is found that the point prone to first ply failure damage is free of any hidden flaw, it can safely be concluded that the shell surface is free of any damage caused due to overloading.

\section{Notations}

$a, b: \quad$ Length and width of the shell

$c$ : $\quad$ Rise of hypar shell

$u, v, w: \quad$ In-plane and transverse displacements

$\alpha, \beta$ : $\quad$ Slopes along the plan directions

$E_{11}, E_{22}, E_{33}$ : Elastic moduli

$G_{12}, G_{13}, G_{23}$ : Shear moduli

$R_{x y}$ : Twist radius of curvature of the hypar shell

1, 2, and 3: Local coordinates of a lamina

$x, y, z: \quad$ Global coordinates of the laminate

$\varepsilon_{x}, \varepsilon_{y}: \quad$ In-plane normal strain components along $x$ - and $y$-axis, respectively

$\gamma_{x y}: \quad$ In-plane shear strain in $x$ - $y$ plane

$\varepsilon_{1}, \varepsilon_{2}$ : In-plane normal strains along 1 and 2 axes of a lamina, respectively 


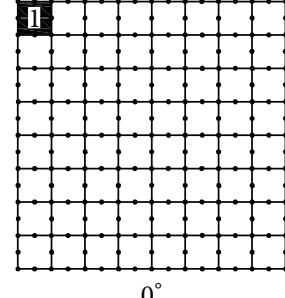

Failure: 1

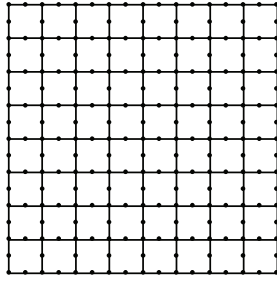

$90^{\circ}$

Failure: 1

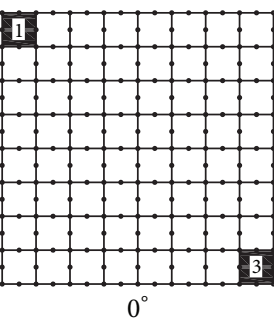

Failure: 5

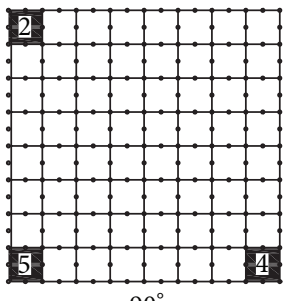

Failure: 5

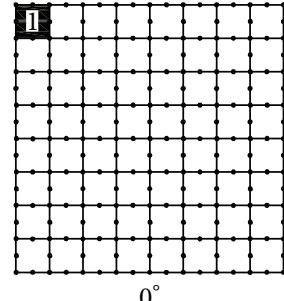

Failure: 2

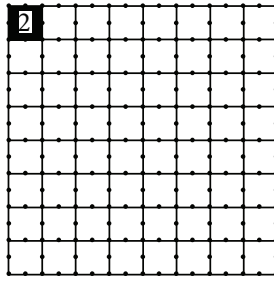

$90^{\circ}$

Failure: 2

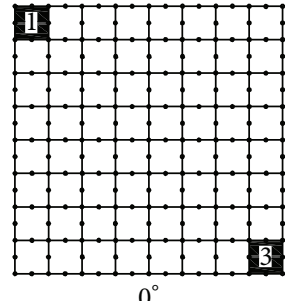

Failure: 3

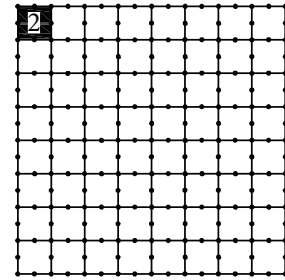

$90^{\circ}$

Failure: 3

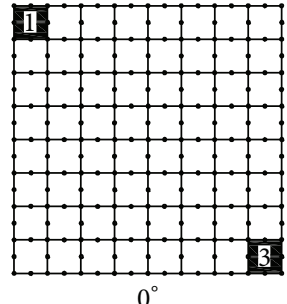

Failure: 4

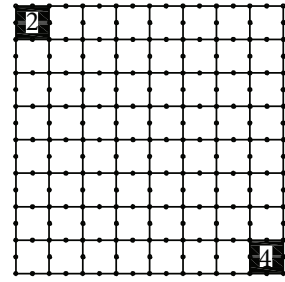

$90^{\circ}$

Failure: 4

(a)
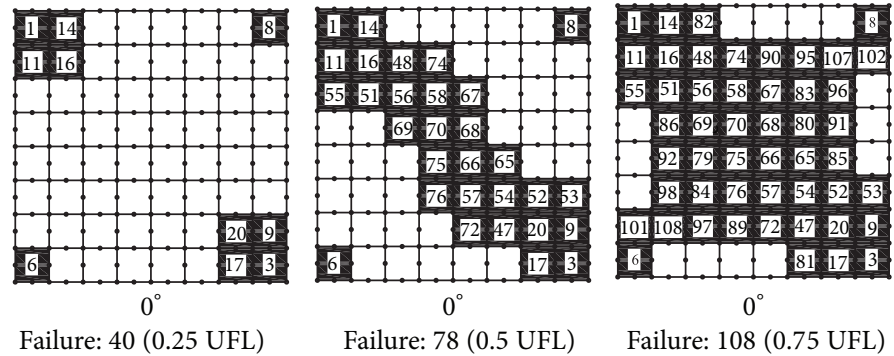

Failure: 78 (0.5 UFL)

Failure: 108 (0.75 UFL)

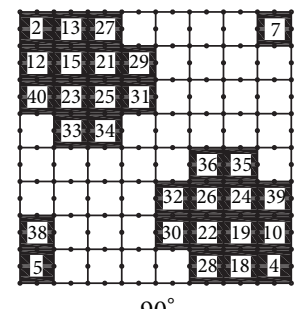

Failure: 40 (0.25 UFL)

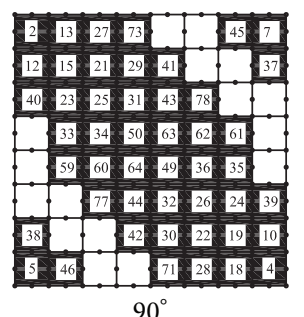

Failure: 78 (0.5 UFL) \begin{tabular}{llllll}
\hline 2 & 13 & 27 & 73 & 105 & 45
\end{tabular}

$\begin{array}{llllllll}12 & 15 & 21 & 29 & 41 & 88 & 103 & 37\end{array}$ $40 \begin{array}{llllll}42 & 25 & 31 & 43 & 78 & 94\end{array}$

$\begin{array}{lllllll}100 & 33 & 34 & 50 & 63 & 62 & 61\end{array}$

$\begin{array}{lllllll}59 & 60 & 64 & 49 & 36 & 35 & 99\end{array}$

\begin{tabular}{lllllll}
\hline 0 & 77 & 44 & 32 & 26 & 24 & 39
\end{tabular}

$\begin{array}{lllllllll}38 & 104 & 87 & 42 & 30 & 22 & 19 & 10\end{array}$

546.1067128184

\section{$90^{\circ}$}

Failure: 108 (0.75 UFL)

(b)

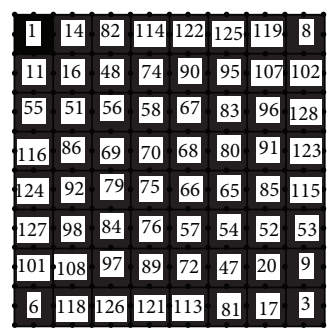

Failure: 128 (UFL)

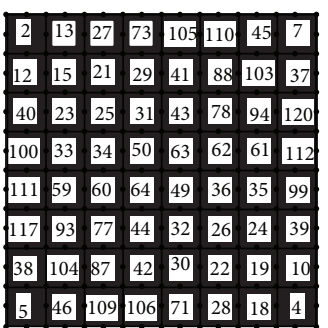

90

Failure: 128 (UFL)

\section{- The shaded portions}

represent the "failed element"

- The number written in shaded portion

represents the "sequence of failure".

(c)

FIgURE 5: (a): Typical failure pattern of type ASCP. (b): Typical failure pattern of type ASCP. (c): Typical failure pattern of type ASCP. 


$\begin{array}{ll}\varepsilon_{6}: & \text { In-plane shear strain in 1-2 plane of a } \\ & \text { lamina } \\ \sigma_{1}, \sigma_{2}, \text { and } \sigma_{6}: & \text { In-plane lamina stresses } \\ v_{i j}: & \text { Poisson's ratio } \\ \xi, \eta: & \text { Natural co-ordinates of isoparametric } \\ & \text { elements } \\ \kappa_{x}, \kappa_{y}, \kappa_{x y}: & \text { Curvatures of the shell due to load } \\ N_{i}: & \text { Interpolation functions } \\ X_{T} \text { and } X_{C}: & \text { Normal stress strengths of a lamina } \\ & \text { along the fiber direction in tension and } \\ & \text { compression respectively } \\ Y_{T} \text { and } Y_{C}: & \begin{array}{l}\text { Normal stress strengths of the matrix } \\ \text { along the perpendicular to the fiber }\end{array} \\ & \text { direction in tension and compression } \\ & \text { respectively } \\ R, S, T: & \text { Shear stress strengths of a lamina } \\ q: & \text { Intensity of uniformly distributed load } \\ w: & \text { Transverse displacement in cm } \\ \bar{w}: & \text { Non-dimensional transverse } \\ & \text { displacement of shell }=\left[w E_{22} h^{3} /\left(q a^{4}\right)\right] .\end{array}$

\section{Conflict of Interests}

The authors declare that there is no conflict of interests regarding the publication of this paper.

\section{Acknowledgment}

The first author gratefully acknowledges the financial assistance of Technical Education Quality Improvement Programme, Phase-II (a World Bank aided project of Government of India) of serial no. 1893 of Jadavpur University, Kolkata 700032, India.

\section{References}

[1] S. Sahoo and D. Chakravorty, "Finite element vibration characteristics of composite hypar shallow shells with various edge supports," Journal of Vibration and Control, vol. 11, no. 10, pp. 1291-1309, 2005.

[2] S. Sahoo and D. Chakravorty, "Finite element bending behaviour of composite hyperbolic paraboloidal shells with various edge conditions," Journal of Strain Analysis, vol. 39, no. 5, pp. 1-15, 2004.

[3] A. N. Nayak and J. N. Bandyopadhyay, "On the free vibration of stiffened shallow shells," Journal of Sound and Vibration, vol. 255, no. 2, pp. 357-382, 2003.

[4] S. B. Singh and A. Kumar, "Postbuckling response and failure of symmetric laminates under in-plane shear," Composites Science and Technology, vol. 58, no. 12, pp. 1949-1960, 1998.

[5] G. Akhras and W. C. Li, "Progressive failure analysis of thick composite plates using the spline finite strip method," Composite Structures, vol. 79, no. 1, pp. 34-43, 2007.

[6] R. Ganesan and D. Y. Liu, "Progressive failure and postbuckling response of tapered composite plates under uni-axial compression," Composite Structures, vol. 82, no. 2, pp. 159-176, 2008 .
[7] J. N. Reddy and A. K. Pandey, "A first-ply failure analysis of composite laminates," Computers and Structures, vol. 25, no. 3, pp. 371-393, 1987.

[8] T. Y. Kam and T. B. Jan, "First-ply failure analysis of laminated composite plates based on the layerwise linear displacement theory," Composite Structures, vol. 32, no. 1-4, pp. 583-591, 1995.

[9] T. Y. Kam, H. F. Sher, T. N. Chao, and R. R. Chang, "Predictions of deflection and first-ply failure load of thin laminated composite plates via the finite element approach," International Journal of Solids and Structures, vol. 33, no. 3, pp. 375-398, 1996.

[10] B. G. Prusty, S. K. Satsangi, and C. Ray, "First ply failure analysis of stiffened panels-a finite element approach," Composite Structures, vol. 51, no. 1, pp. 73-81, 2001.

[11] Y. V. Satish Kumar and A. Srivastava, "First ply failure analysis of laminated stiffened plates," Composite Structures, vol. 60, no. 3, pp. 307-315, 2003.

[12] P. Pal and C. Ray, "Progressive failure analysis of laminated composite plates by finite element method," Journal of Reinforced Plastics and Composites, vol. 21, no. 16, pp. 1505-1513, 2002.

[13] T. P. Philippidis and A. E. Antoniou, "A progressive damage FEA model for glass/epoxy shell structures," Journal of Composite Materials, vol. 47, no. 5, pp. 623-637, 2013.

[14] B. Ellul, D. Camilleri, and J. C. Betts, "A progressive failure analysis applied to fiber-reinforced composite plates subject to out-of-plane bending," Mechanics of Composite Materials, vol. 49, no. 6, pp. 605-620, 2014.

[15] S. Tolson and N. Zabaras, "Finite element analysis of progressive failure in laminated composite plates," Computers and Structures, vol. 38, no. 3, pp. 361-376, 1991.

[16] B. G. Prusty, "Progressive failure analysis of laminated unstiffened and stiffened composite panels," Journal of Reinforced Plastics and Composites, vol. 24, no. 6, pp. 633-642, 2005.

[17] J. N. Reddy, "Exact solutions of moderately thick laminated shells," Journal of Engineering Mechanics, vol. 110, no. 5, pp. 794809, 1984. 

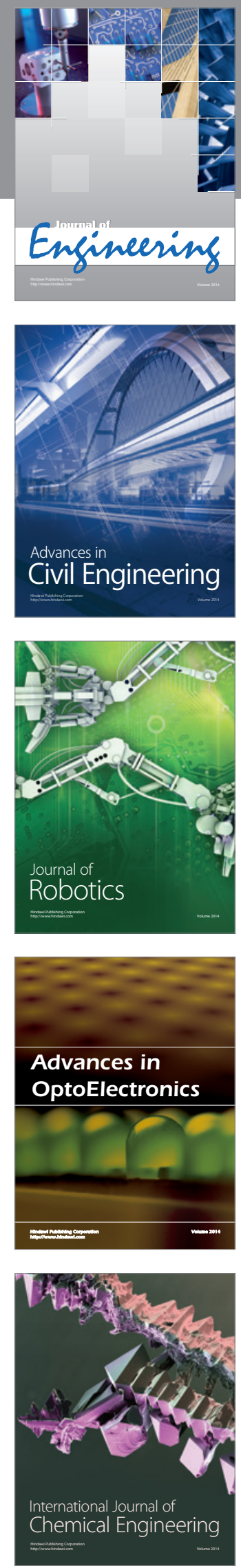

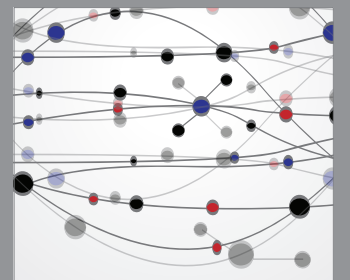

The Scientific World Journal
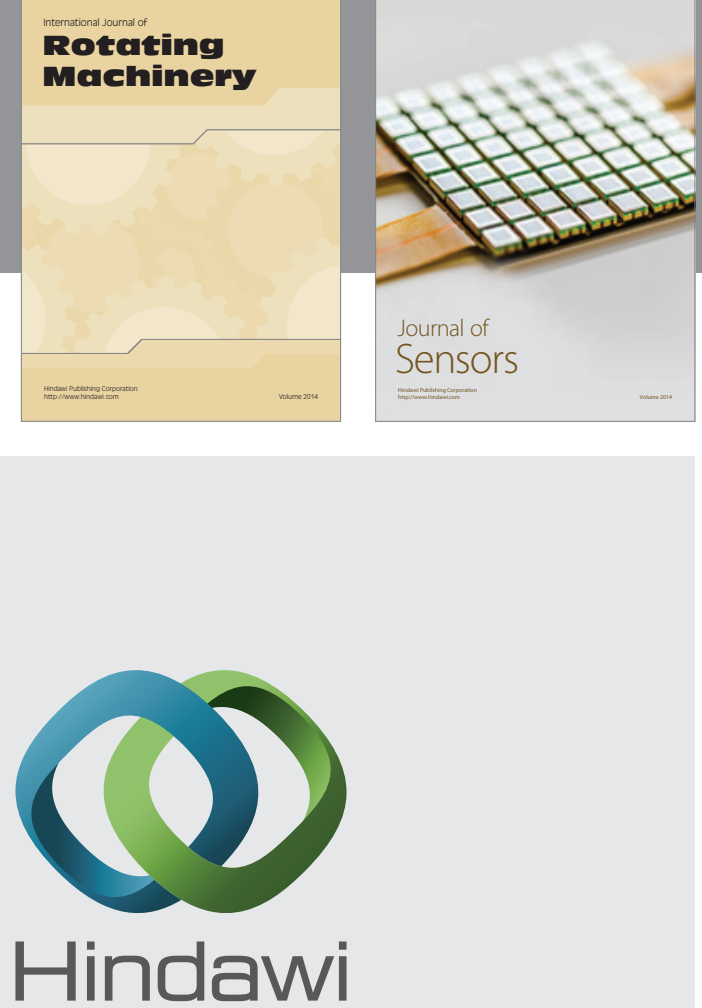

Submit your manuscripts at http://www.hindawi.com
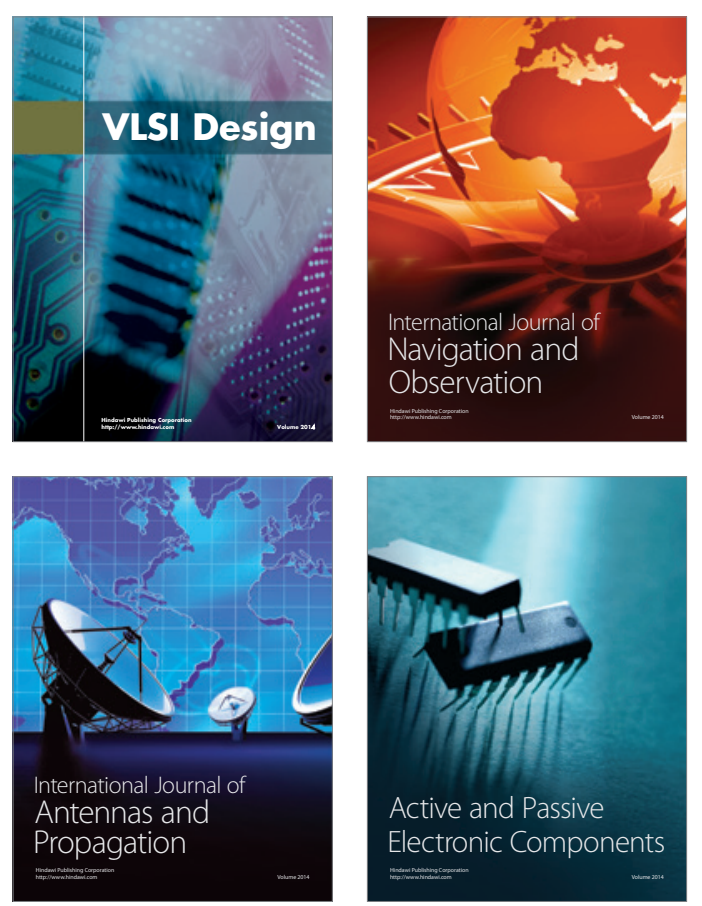
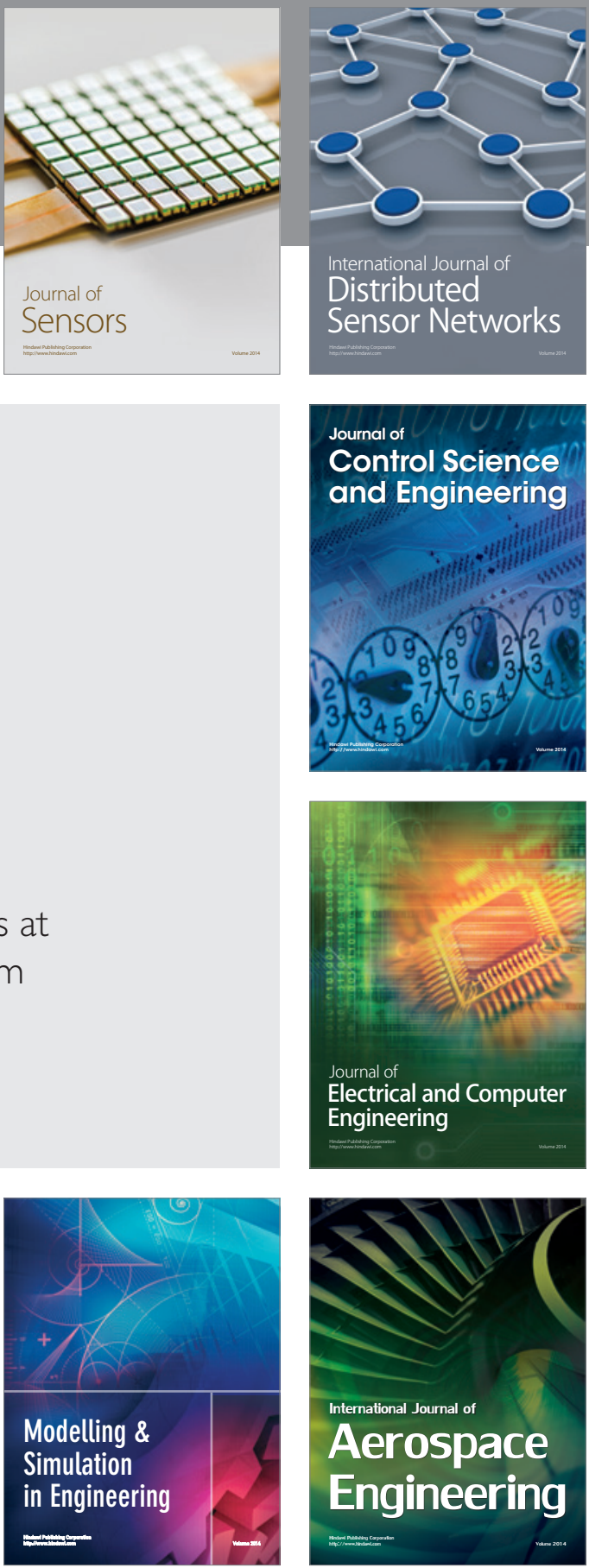

Journal of

Control Science

and Engineering
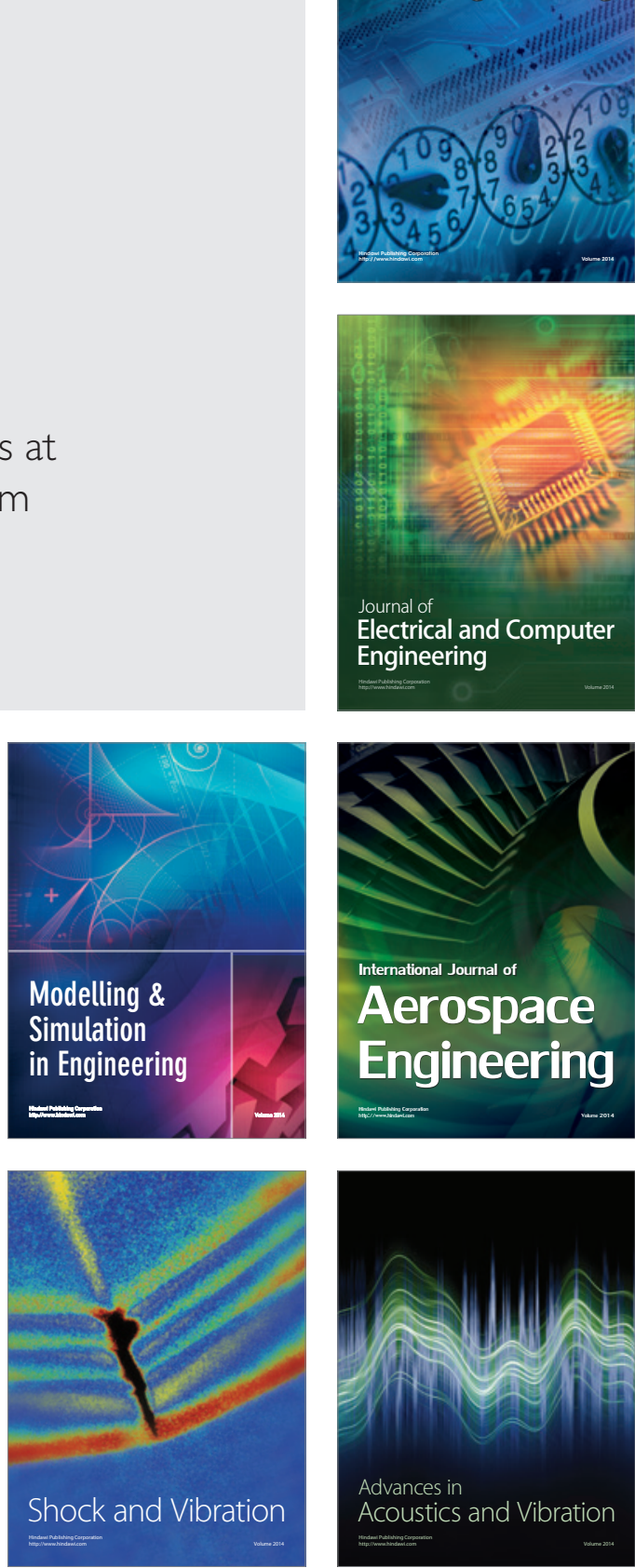